medRxiv preprint doi: https://doi.org/10.1101/2020.11.23.20237495; this version posted November 27, 2020. The copyright holder for this preprint (which was not certified by peer review) is the author/funder, who has granted medRxiv a license to display the preprint in perpetuity.

It is made available under a CC-BY 4.0 International license .

\title{
Meningioma epigenetic grouping reveals biologic drivers and therapeutic vulnerabilities
}

\section{Authors}

Abrar Choudhury 1,2,3,4, Stephen T. Magill ${ }^{1,2 \#}$, Charlotte D. Eaton ${ }^{1,2}$, Briana C. Prager ${ }^{5}$, William C. Chen ${ }^{1,2}$, Kyounghee Seo ${ }^{1,2}$, Calixto-Hope G. Lucas ${ }^{1,2,6}$, Javier E. Villanueva-Meyer ${ }^{7}$, Tai-Chung Lam ${ }^{8}$, Jenny KanSuen Pu ${ }^{9}$, Lai-Fung Li ${ }^{9}$, Gilberto Ka-Kit Leung ${ }^{9}$, Harish N. Vasudevan ${ }^{1,2}$, S. John Liu ${ }^{1,2}$, Jason W. Chan ${ }^{1}$, Zhixin Qiu ${ }^{5}$, Michael Y. Zhang ${ }^{1,2}$, Michael V. Martin², Matthew S. Susko1, Steve E. Braunstein ${ }^{1}$, Nancy Ann Oberheim Bush², Jessica Schulte ${ }^{2,10}$, Nicholas Butowski2,10, Penny K. Sneed ${ }^{1}$, Mitchel S. Berger ${ }^{2}$, Arie Perry ${ }^{2,6}$, Joanna J. Phillips ${ }^{2,6}$, David A. Solomon ${ }^{6}$, Joseph F. Costello², Michael W. McDermott ${ }^{2,11}$, Jeremy N. Rich ${ }^{5 \#}$, David R. Raleigh ${ }^{1,2 \#}$

\section{Affiliations}

${ }^{1}$ Department of Radiation Oncology, University of California San Francisco, San Francisco, CA 94143, USA.

${ }^{2}$ Department of Neurological Surgery, University of California San Francisco, San Francisco, CA 94143, USA.

${ }^{3}$ Medical Scientist Training Program, University of California San Francisco, San Francisco, CA 94143, USA.

${ }^{4}$ Biomedical Sciences Graduate Program, University of California, San Francisco, San Francisco, CA 94143, USA.

${ }^{5}$ Department of Medicine, University of California San Diego, San Diego, CA 92093, USA.

${ }^{6}$ Department of Pathology, University of California San Francisco, San Francisco, CA 94143, USA.

${ }^{7}$ Department of Radiology and Biomedical Imaging, University of California San Francisco, San Francisco, CA 94143, USA.

${ }^{8}$ Department of Clinical Oncology, The University of Hong Kong, Pokfulam, Hong Kong.

${ }^{9}$ Department of Neurosurgery, Division of Neurosurgery, The University of Hong Kong, Pokfulam, Hong Kong.

${ }^{10}$ Department of Neurology, University of California San Francisco, San Francisco, CA 94143, USA.

${ }^{11}$ Miami Neuroscience Institute, Baptist Health, Miami, FL 33176, USA.

\#Correspondence to david.raleigh@ucsf.edu, drjeremyrich@gmail.com, stephen.t.magill@gmail.com 


\section{SUMMARY}

Meningiomas arising from the meningothelial central nervous system lining are the most common primary intracranial tumors, and a significant cause of neurologic morbidity and mortality ${ }^{1}$. There are no effective medical therapies for meningioma patients ${ }^{2,3}$, and new treatments have been encumbered by limited understanding of meningioma biology. DNA methylation profiling provides robust classification of central nervous system tumors ${ }^{4}$, and can elucidate targets for molecular therapy ${ }^{5}$. Here we use DNA methylation profiling on 565 meningiomas integrated with genetic, transcriptomic, biochemical, and single-cell approaches to show meningiomas are comprised of 3 epigenetic groups with distinct clinical outcomes and biological features informing new treatments for meningioma patients. Merlin-intact meningiomas (group A, 34\%) have the best outcomes and are distinguished by a novel apoptotic tumor suppressor function of NF2/Merlin. Immune-enriched meningiomas (group B, 38\%) have intermediate outcomes and are distinguished by immune cell infiltration, HLA expression, and lymphatic vessels. Hypermitotic meningiomas (group C, 28\%) have the worst outcomes and are distinguished by convergent genetic mechanisms misactivating the cell cycle. Consistently, we find cell cycle inhibitors block meningioma growth in cell culture, organoids, xenografts, and patients. Our results establish a framework for understanding meningioma biology, and provide preclinical rationale for new therapies to treat meningioma patients. 


\section{MAIN TEXT}

\section{Meningiomas are comprised of 3 epigenetic groups}

To identify biologic drivers and therapeutic vulnerabilities underlying meningioma, DNA methylation profiling was performed on 565 meningiomas from patients with comprehensive clinical follow-up who were treated at 2 independent institutions from 1991 to 2019. Consistent with typical meningioma outcomes, local freedom from recurrence (LFFR) and overall survival (OS) were worse with higher World Health Organization (WHO) grade, recurrent presentation, or subtotal resection (Extended Data Fig. 1a). Meningiomas were stratified by institution into a 200-sample discovery cohort from the University of California San Francisco (median follow-up 6.3 years), and a consecutive 365-sample validation cohort from The University of Hong Kong (median follow-up 5.3 years) (Extended Data Table 1). Prior DNA methylation studies have identified epigenetic groups of meningiomas with distinct clinical outcomes ${ }^{6-9}$, suggesting DNA methylation profiles may encode biologic information that could inform new treatments for meningioma patients. However, meningiomas that are resistant to current therapies have an abundance of genomic deletions and amplifications ${ }^{9,10}$, which can bias DNA methylation analyses ${ }^{11}$. Prior studies have not accounted for these confounding factors, and have not provided mechanistic or functional validation of meningioma groups. Thus, opportunities exist to build on foundational observations from initial meningioma DNA methylation studies, particularly through new bioinformatic techniques clarifying epigenetic groups in the context of copy number variation (CNV), mechanistic interrogation of epigenetic groups, and functional discovery of new therapies for meningioma patients.

Unsupervised hierarchical clustering of DNA methylation probes, controlled for artifacts from genomic deletions and amplifications using the SeSAMe preprocessing pipeline ${ }^{11}$, revealed 3 epigenetic groups of meningiomas in the discovery cohort (Fig. 1a). K-means consensus clustering validated 3 groups as the optimal number in the discovery and validation cohorts (Fig. 1b and Extended Data Fig. 1b). To assign meningiomas from the validation cohort into epigenetic groups, a multi-class support vector machine classifier was constructed that performed with $97.9 \%$ accuracy when classifying random samples from the discovery cohort $\left(95 \% \mathrm{Cl} 89.2-99.9 \%, \mathrm{p}<2.2 \times 10^{-16}\right)$. Kaplan-Meier analyses of the discovery and validation cohorts showed epigenetic groups were distinguished by differences in LFFR and OS (Fig. 1C), and correlated with prognostic clinical features of grade, sex, prior radiotherapy, and location (Fig. 1d and Extended Data Fig. 2a) ${ }^{12}$. Nevertheless, epigenetic groups were independently prognostic for outcomes on Kaplan-Meier analysis across WHO grades (Extended Data Fig. 2b, c), and on multivariable regression accounting for grade, extent of resection and other clinical features (Extended Data Table 2).

There were abundant CNVs across epigenetic groups (Extended Data Fig. 3a), underscoring the importance of accounting for genomic deletions and amplifications in meningioma DNA methylation profiles. Group C meningiomas had the worst outcomes (Fig. 1C) and had more CNVs compared to tumors from other groups (Fig. 1e and Extended Data Fig. 3b). Group A meningiomas had the best outcomes (Fig. 1C) and included $76 \%$ of the tumors with gain of chromosome 5 (Extended Data Fig. $\mathbf{3 b}$ ), which is reported in meningiomas with favorable outcomes after surgery or radiotherapy ${ }^{10,13}$. Group B meningiomas had intermediate outcomes (Fig. 1c) and had fewer CNVs compared to tumors from other groups (Fig. 1e). 


\section{Group A meningiomas are Merlin-intact}

Meningiomas are common in patients with neurofibromatosis type 2, a complex autosomal disorder caused by loss of the tumor suppressor NF2 on chromosome $22 q^{14}$. NF2 is also the most recurrently mutated gene in sporadic ${ }^{15,16}$ and radiation-induced ${ }^{17}$ meningiomas. Patients in the discovery or validation cohorts with neurofibromatosis type $2(n=18)$ or radiation-induced meningiomas $(n=34)$ overwhelmingly had group B or C meningiomas (96\%), and NF2 was lost in $86 \%$ of group B and C tumors, but only in $17 \%$ of group A meningiomas (Fig. 2a). RNA sequencing of the 200 -sample discovery cohort confirmed lower NF2 expression in group B and C meningiomas compared to group A tumors (Fig. 2b). Amplicon-based DNA sequencing on 65 samples from the discovery cohort confirmed that accounting for mutations, insertions, or deletions in NF2 did not alter the frequency of NF2 alterations in group A meningiomas (Extended Data Table 3). The combined distribution of NF2 CNVs and somatic short variants showed $89 \%$ of group A meningiomas encoded at least 1 wildtype copy of NF2 (Fig. 2c), which translated to expression of Merlin protein (Fig. 2d). TRAF7 somatic short variants are mutually exclusive to NF2 inactivating variants in meningiomas ${ }^{15,18}$, and were enriched in group A (Merlin-intact) meningiomas compared to tumors from other groups (Extended Data Table 4). However, many Merlinintact meningiomas did not encode TRAF7 somatic short variants, suggesting the epigenetic group of meningiomas with the best outcomes may not be unified by a single oncogenic mechanism. In support of this hypothesis, meningioma histologic subtypes associated with $\mathrm{AKT} 1^{\mathrm{E} 17 \mathrm{~K}}$ somatic short variants were also enriched in Merlin-intact meningiomas compared to tumors from other groups (Extended Data Table 4) ${ }^{19}$.

Merlin has pleiotropic tumor suppressor functions at the plasma membrane ${ }^{20,21}$ and nucleus ${ }^{22}$ in schwannoma cells, but Merlin tumor suppressor functions in meningiomas are incompletely understood. M10G and IOMM-Lee meningioma cells express Merlin ${ }^{23,24}$, and Merlin suppression in these cells increased meningioma cell proliferation (Fig. 2e, $\mathbf{f}$ and Extended Data Fig. 4a, b, c). To identify gene expression programs underlying Merlin tumor suppressor functions in meningiomas, RNA sequencing was performed on triplicate M10G cultures stably expressing the CRISPR interference (CRISPRi) components dCas9-KRAB ${ }^{25}$ and non-targeting control sgRNA (sgNTC), sgRNA targeting NF2 (sgNF2), or sgNF2 with NF2 rescue (Fig. 2e). Differential expression and ontology analyses revealed Merlin induced apoptotic interferon pathways ${ }^{26-29}$ previously unknown to be associated with either Merlin tumor suppressor functions or meningioma biology (Fig. $\mathbf{2 g}, \mathbf{h}$ and Extended Data Table 5). To test this mechanistically, M10G ${ }^{\mathrm{dCas} 9-\mathrm{KRAB}}$ and IOMM-Lee cultures were treated with the cytotoxic chemotherapy actinomycin D, revealing Merlin protected meningioma cells from apoptosis (Fig. 2i, j, and Extended Data Fig. 4d). These data shed light on a novel apoptotic tumor suppressor function of Merlin underlying the epigenetic group of meningiomas with the best outcomes that is lost in groups that are resistant to current therapies (Fig. 1c).

\section{Group B meningiomas are Immune-enriched}

The relative reduction in group $\mathrm{B}$ meningioma CNVs suggests bulk bioinformatic analyses of meningiomas may be influenced by non-tumor cells in the meningioma microenvironment (Fig. 1e). SeSAMe ${ }^{11}$ cell-type deconvolution of DNA methylation profiles revealed enrichment of immune cells in group B meningiomas compared to tumors from other groups (Fig. 3a). PAMES ${ }^{30}$ tumor purity analysis and $x$ Cell $^{31}$ RNA sequencing deconvolution validated these findings (Fig. 3b, c, and Extended Data Fig. 5a, b). Differential expression and gene ontology analyses showed enrichment of immune genes in 
Immune-enriched (group B) meningiomas (Extended Data Fig. 5c and Extended Data Table 6), and immunohistochemistry revealed T cell enrichment in Immune-enriched meningiomas compared to tumors from other groups (Fig. 3d). To validate these findings, single-cell RNA sequencing was performed on 57,114 cells from 8 meningioma samples representing each epigenetic group (Extended Data Fig. 6a). Reduced dimensionality clusters of meningioma and non-meningioma cells were identified by chromosome 22q loss (Extended Data Fig. 6b). Non-meningioma cell clusters with retained chromosome $22 q$ were classified by expression of immune, neural, and vascular marker genes (Extended Data Fig. 6c, d and Extended Data Table 7). Meningioma cell clusters with chromosome $22 q$ loss were distinguished by uniquely expressed marker genes (Extended Data Fig. 6c, d and Extended Data Table 7). In sum, single-cell transcriptomes revealed more immune cells in Immuneenriched meningiomas compared to tumors from other groups (Fig. 3e). Moreover, analysis of our previously reported DNA methylation profiles on 86 spatially distinct meningioma samples from 13 tumors $^{23}$ revealed $92 \%$ of samples classified in concordance with the consensus epigenetic group of each tumor (Extended Data Fig. 5d). Thus, epigenetic grouping of meningiomas is not confounded by intratumor heterogeneity or sampling bias, suggesting coordinated genetic mechanisms underlie a novel group of Immune-enriched meningiomas that is distinguished by immune cell infiltration.

$H L A$ loss can decrease immune infiltration in cancer ${ }^{32} .88 \%$ of meningiomas with $H L A$ loss were Merlin-intact or group $\mathrm{C}$ tumors (Fig. 3f), and $H L A$ expression was increased in Immune-enriched meningiomas compared to tumors from other groups (Fig. $\mathbf{3 g}$ ). Single-cell transcriptomes showed increased $H L A$ expression in Immune-enriched meningioma cells compared to meningioma cells from other groups (Fig. 3h), suggesting HLA differences across epigenetic groups were not confounded by non-tumor cells. Analysis of our previously reported matched whole exome sequencing and DNA methylation profiling on 25 meningiomas overlapping with the discovery cohort revealed no instances of $H L A$ loss of heterozygosity in Immune-enriched meningiomas (9 Immune-enriched, 16 non-Immuneenriched $)^{9}$. Thus, HLA expression may contribute to immune infiltration in Immune-enriched meningiomas compared to tumors from other groups.

Meningeal lymphatic vessels are necessary for intracranial immune surveillance ${ }^{33-36}$, and are concentrated near dural venous sinuses ${ }^{33}$, but are not known to influence intracranial tumor immune infiltration. Preoperative magnetic resonance imaging from the discovery cohort showed both Immuneenriched and group C meningiomas were more likely to involve dural venous sinuses than Merlin-intact tumors (Fig. 3i, j), suggesting immune infiltration and meningeal lymphatics in Immune-enriched meningiomas were not solely a byproduct of tumor location. Immune-enriched meningiomas had hypomethylation (Fig. 3k) and increased expression (Fig. 3I) of meningeal lymphatic genes such as LYVE1 and CCL21 compared to tumors from other groups ${ }^{36-38}$. Immunofluorescence for LYVE1 and the lymphatic marker PROX $1^{39}$ confirmed lymphatic enrichment in Immune-enriched meningiomas compared to tumors from other groups (Fig. $\mathbf{3 m}$ ). Thus, in addition to $H L A$ expression, lymphatic vessels may also contribute to immune infiltration in Immune-enriched meningiomas compared to tumors from other groups.

\section{Group C meningiomas are Hypermitotic}

High-grade meningiomas are defined by brisk cell proliferation leading to local recurrence and death in $50-90 \%$ of patients ${ }^{40,41}$. We previously reported FOXM1 is a key transcription factor for meningioma cell proliferation ${ }^{9}$, and FOXM1 target genes are reliable biomarkers for meningioma recurrence ${ }^{42}$. Cell 
proliferation was highest in group C meningiomas (Fig. 4a), and RNA sequencing and gene ontology analysis revealed the FOXM1 transcriptional program was enriched in Hypermitotic (group C) meningiomas compared to tumors from other groups (Fig. 4b, Extended Data Fig. 7a, and Extended Data Table 6). Immunohistochemistry and immunofluorescence showed FOXM1 protein localized to dividing meningioma cells, and correlated with meningioma cell proliferation across epigenetic groups (Fig. 4c, d). To define FOXM1 targets in meningioma, differentially expressed genes with FOXM1 binding motifs were analyzed in our previously reported matched RNA sequencing, H3K27ac ChIP sequencing, and DNA methylation profiling on 25 meningiomas (15 Hypermitotic, 10 non-Hypermitotic) ${ }^{43}$. FOXM1 target genes in Hypermitotic meningiomas regulated the DNA damage response, the cell cycle, and tumor metabolism (Extended Data Fig. 7b), suggesting FOXM1 promotes treatment resistance in the epigenetic group of meningiomas with the worst outcomes after treatment with current therapies (Fig. 1c).

Druggable somatic short variants in meningiomas are rare and are not associated with adverse outcomes $^{10,14-19,44-49}$, with rare exceptions ${ }^{50-53}$. Differential expression of enhancers and super-enhancers within the consensus meningioma peakset revealed the enhancer landscape of Hypermitotic meningiomas was dominated by epigenetic mechanisms and transcription factors, such as FOXM1, that are impractical pharmacologic targets (Extended Data Fig. 8). However, Hypermitotic meningiomas had more large genomic deletions and amplifications compared to tumors from other groups (Fig. 1e and Extended Data Fig. 3). Thus, CNVs contributing to cell cycle misactivation may harbor therapeutic vulnerabilities that could be used to inform new treatments for meningioma patients.

Loss of the endogenous CDK4/6 inhibitors $C D K N 2 A / B$ is associated with worse outcomes in multiple brain tumors ${ }^{54}$, including meningiomas ${ }^{53} .62 \% C D K N 2 A / B$ losses occurred in Hypermitotic meningiomas and were associated with worse LFFR (Fig. 4e). CDKN2A/B was also hypermethylated in Hypermitotic meningiomas compared to tumors from other groups (Fig. 4f), a reported alternate mechanism of CDK4/6 misactivation in cancer ${ }^{55,56}$. To identify reagents to study meningioma epigenetic groups, DNA methylation profiling and epigenetic classification were performed on 9 meningioma cell lines. M10G cells classified among Immune-enriched meningiomas and expressed $C D K N 2 A / B$ (Extended Data Table 5). Stable suppression of CDKN2A or CDKN2B in M10G ${ }^{\text {dCas9-KRAB }}$ cells using sgRNAs increased cell proliferation (Fig. $\mathbf{4 g}, \mathbf{h}$ ), and re-classified triplicate M10G ${ }^{\mathrm{dCas9}-K R A B}$ DNA methylation profiles among Hypermitotic meningiomas (Fig. 4i). In contrast, DNA methylation profiles of triplicate M10G ${ }^{\mathrm{dCas} 9-\mathrm{KRAB}}$ cultures stably expressing sgNF2 (Fig. 2e), which also increased cell proliferation (Fig. 2f), remained classified among Immune-enriched meningiomas (Fig. 4i). These data suggest coordinated genetic events underlie a novel group of Hypermitotic meningiomas that is distinguished by cell cycle misactivation.

Not all Hypermitotic meningiomas have $C D K N 2 A / B$ loss (Fig. 4e). Thus, additional mechanisms must exist to drive the cell cycle in Hypermitotic tumors. Recurrent transcription factor binding motifs were present in H3K27ac ChIP sequencing troughs at the CDK6 and FOXM1 loci (Extended Data Table 8). USF1 is a transcription factor on chromosome 1q, which is associated with poor outcomes in other brain tumors $^{57}$. USF1 binding sites were occupied in the promoters of CDK6 and FOXM1 (Fig. 4j); 88\% of USF1 gains occurred in Hypermitotic meningiomas (Fig. 4k and Extended Data Fig. 3b); and USF1 gain was associated with worse LFFR (Fig. 4k). Moreover, USF1 bound to the CDK6 and FOXM1 promoters (Fig. 4I) and induced CDK6 expression (Fig. $\mathbf{4 m}, \mathbf{n}$ ) in meningioma cells, demonstrating USF1 is a regulator of CDK6 and FOXM1 in meningioma. In sum, convergent genetic mechanisms misactivate 
the cell cycle in Hypermitotic meningiomas, suggesting cytostatic therapies targeting the cell cycle may be effective treatments for meningiomas that are resistant to current therapies.

\section{Cell cycle inhibition blocks meningioma growth}

In comparison to Merlin-intact meningiomas, Immune-enriched and Hypermitotic tumors (i) have intermediate and poor outcomes, respectively (Fig. 1c, 5a); (ii) exist along a continuum of cell cycle misactivation (Fig. 4a); and (iii) are distinguished by multiple resistance mechanisms diminishing the efficacy of cytotoxic therapies (Fig. 2i, j, and Extended Data Fig. 7b). Thus, to interrogate the cell cycle as a therapeutic target in meningioma, the clinical CDK4/6 inhibitors abemaciclib, palbociclib, and ribociclib ${ }^{58}$ were tested in cell culture, organoids, and xenografts using Immune-enriched and Hypermitotic meningioma cells (Fig. 5a). CDK4/6 inhibitors blocked clonogenic growth of Immuneenriched and Hypermitotic meningioma cells (Fig. 5b). Suppression of CDKN2A or CDKN2B increased the efficacy of CDK4/6 inhibition in M10G ${ }^{\text {dCas9-KRAB }}$ cells (Fig. 5c), but was not necessary for responses to treatment. To test this therapeutic strategy in the context of a tumor microenvironment, Hypermitotic meningioma cells were co-cultured with cerebral organoids comprised of pre-differentiated human pluripotent stem-cell derived astrocytes. We previously reported this model restores intratumor heterogeneity in meningioma cells ${ }^{23}$, and intratumor heterogeneity is a source of resistance to cancer treatments ${ }^{59}$. Nevertheless, CDK4/6 inhibition attenuated the growth of Hypermitotic meningioma cells in co-culture with cerebral organoids (Fig. 5d). To define the pharmacodynamics and efficacy of cell cycle inhibitors in vivo, RB-intact meningioma xenografts were treated with CDK4/6 inhibitors. CDK4/6 blockade decreased expression of phospho-RB (Fig. 5e), inhibited cell proliferation (Fig. 5f), attenuated xenograft growth (Fig. 5g), and prolonged survival in mice (Fig. 5h). These data provide preclinical rationale to treat patients with Immune-enriched or Hypermitotic meningiomas with cell cycle inhibitors. More broadly, our mechanistic and functional results validate the first biomarker-based molecular treatment for meningiomas with adverse outcomes.

In support of our preclinical investigations, we have observed encouraging early results with compassionate use of CDK4/6 inhibitors to treat human meningiomas that are resistant to surgery and radiotherapy (Fig. 5i). Formalized clinical trials to establish the efficacy of this and other molecular therapies for meningiomas will require rigorous patient selection and biologic stratification. In anticipation, data from the discovery and validation cohorts were used to develop prognostic nomograms integrating clinical features predicting meningioma recurrence alongside epigenetic groups predicting meningioma biology (Fig. 5j and Extended Data Fig. 9a). Although DNA methylation profiling is a powerful tool for biologic discovery, clinical adoption of this technique has been hampered by a lack of medical indications. The data presented here establish an urgent need for clinical DNA methylation profiling to stratify meningioma patients for molecular treatments. In the interim, recursive partitioning analysis of CNV profiles can be used to approximate epigenetic groups of meningiomas and improve prognostic models for meningioma recurrence (Extended Data Fig. 9b-f).

In conclusion, our results shed light on biochemical, cellular, and genomic mechanisms underlying the most common primary intracranial tumor. By accounting for artifacts from CNVs and integrating epigenetic, genetic, transcriptomic, biochemical, and single-cell approaches, we identify 3 epigenetic groups of meningiomas with distinct clinical and biological features that can inform new treatments for meningioma patients. 


\section{Acknowledgements}

The authors thank Aaron Tward and Adam Abate for comments and reagents, Anny Shai and the staff of the UCSF Brain Tumor Center Biorepository and Pathology Core, Tomoko Ozawa and the staff of the UCSF Brain Tumor Center Preclinical Therapeutics Core, and Eric Chow and the staff of the UCSF Center for Advanced Technology. This study was supported by the UCSF Wolfe Meningioma Program Project and NIH grants F30CA246808 and T32GM007618 to A.C.; NIH grant P50CA097257 to J.J.P.; the UCSF Wolfe Meningioma Program Project and NIH grant F32CA213944 to S.T.M.; the UCSF Wolfe Meningioma Program Project to C.D.E., J.E.V-M., H.N.V., S.E.B., N.A.O.B., J.S., and N.B.; and the UCSF Physician Scientist Scholar Program, the UCSF Wolfe Meningioma Program Project, and NIH grant K08CA212279 to D.R.R.

\section{References}

1. Ostrom, Q. T. et al. CBTRUS Statistical Report: Primary Brain and Other Central Nervous System Tumors Diagnosed in the United States in 2012-2016. Neuro-Oncol. 21, v1-v100 (2019).

2. Brastianos, P. K. et al. Advances in multidisciplinary therapy for meningiomas. Neuro-Oncol. 21, i18i31 (2019).

3. Wen, P. Y., Quant, E., Drappatz, J., Beroukhim, R. \& Norden, A. D. Medical therapies for meningiomas. J. Neurooncol. 99, 365-378 (2010).

4. Capper, D. et al. DNA methylation-based classification of central nervous system tumours. Nature 555, 469-474 (2018).

5. Cavalli, F. M. G. et al. Intertumoral Heterogeneity within Medulloblastoma Subgroups. Cancer Cel/ 31, 737-754.e6 (2017).

6. Sahm, F. et al. DNA methylation-based classification and grading system for meningioma: a multicentre, retrospective analysis. Lancet Oncol. 18, 682-694 (2017).

7. Olar, A. et al. Global epigenetic profiling identifies methylation subgroups associated with recurrencefree survival in meningioma. Acta Neuropathol. (Berl.) 133, 431-444 (2017).

8. Nassiri, F. et al. DNA methylation profiling to predict recurrence risk in meningioma: development and validation of a nomogram to optimize clinical management. Neuro-Oncol. (2019) doi:10.1093/neuonc/noz061.

9. Vasudevan, H. N. et al. Comprehensive Molecular Profiling Identifies FOXM1 as a Key Transcription Factor for Meningioma Proliferation. Cell Rep. 22, 3672-3683 (2018).

10. Bi, W. L. et al. Genomic landscape of intracranial meningiomas. J. Neurosurg. 125, 525-535 (2016).

11. Zhou, W., Triche, T. J., Laird, P. W. \& Shen, H. SeSAMe: reducing artifactual detection of DNA methylation by Infinium BeadChips in genomic deletions. Nucleic Acids Res. 46, e123-e123 (2018).

12. Gennatas, E. D. et al. Preoperative and postoperative prediction of long-term meningioma outcomes. PLOS ONE 13, e0204161 (2018).

13. Abedalthagafi, M. S. et al. Angiomatous meningiomas have a distinct genetic profile with multiple chromosomal polysomies including polysomy of chromosome 5. Oncotarget 5, 10596-10606 (2014).

14. Evans, Dg. R. Neurofibromatosis type 2 (NF2): A clinical and molecular review. Orphanet J. Rare Dis. 4, 1-11 (2009).

15. Clark, V. E. et al. Genomic analysis of non-NF2 meningiomas reveals mutations in TRAF7, KLF4, AKT1, and SMO. Science 339, 1077-1080 (2013). 
16. Brastianos, P. K. et al. Genomic sequencing of meningiomas identifies oncogenic SMO and AKT1 mutations. Nat. Genet. 45, 285-289 (2013).

17. Agnihotri, S. et al. Therapeutic radiation for childhood cancer drives structural aberrations of NF2 in meningiomas. Nat. Commun. 8, 186 (2017).

18. Reuss, D. E. et al. Secretory meningiomas are defined by combined KLF4 K409Q and TRAF7 mutations. Acta Neuropathol. (Berl.) 125, 351-358 (2013).

19. Sahm, F. et al. AKT1E17K mutations cluster with meningothelial and transitional meningiomas and can be detected by SFRP1 immunohistochemistry. Acta Neuropathol. (Berl.) 126, 757-762 (2013).

20. Curto, M., Cole, B. K., Lallemand, D., Liu, C.-H. \& McClatchey, A. I. Contact-dependent inhibition of EGFR signaling by Nf2/Merlin. J. Cell Biol. 177, 893-903 (2007).

21. Chiasson-MacKenzie, C. et al. NF2/Merlin mediates contact-dependent inhibition of EGFR mobility and internalization via cortical actomyosin. J Cell Biol 211, 391-405 (2015).

22. Li, W. et al. Merlin/NF2 Suppresses Tumorigenesis by Inhibiting the E3 Ubiquitin Ligase CRL4DCAF1 in the Nucleus. Cell 140, 477-490 (2010).

23. Magill, S. T. et al. Multiplatform genomic profiling and magnetic resonance imaging identify mechanisms underlying intratumor heterogeneity in meningioma. Nat. Commun. 11, 4803 (2020).

24. Lee, W. H. Characterization of a newly established malignant meningioma cell line of the human brain: IOMM-Lee. Neurosurgery 27, 389-395; discussion 396 (1990).

25. Gilbert, L. A. et al. Genome-Scale CRISPR-Mediated Control of Gene Repression and Activation. Cell 159, 647-661 (2014).

26. Karki, R. et al. Interferon regulatory factor 1 regulates PANoptosis to prevent colorectal cancer. JCI Insight 5, (2020).

27. Ye, L. et al. Interferon Consensus Sequence-Binding Protein 8, a Tumor Suppressor, Suppresses Tumor Growth and Invasion of Non-Small Cell Lung Cancer by Interacting with the Wnt/ $\beta$-Catenin Pathway. Cell. Physiol. Biochem. Int. J. Exp. Cell. Physiol. Biochem. Pharmacol. 51, 961-978 (2018).

28. Luo, $X$. et al. The tumor suppressor interferon regulatory factor 8 inhibits $\beta$-catenin signaling in breast cancers, but is frequently silenced by promoter methylation. Oncotarget 8, 48875-48888 (2017).

29. Ohsugi, T. et al. Anti-apoptotic effect by the suppression of IRF1 as a downstream of Wnt/ 3 -catenin signaling in colorectal cancer cells. Oncogene 38, 6051-6064 (2019).

30. Benelli, M., Romagnoli, D. \& Demichelis, F. Tumor purity quantification by clonal DNA methylation signatures. Bioinforma. Oxf. Engl. 34, 1642-1649 (2018).

31. Aran, D., Hu, Z. \& Butte, A. J. xCell: digitally portraying the tissue cellular heterogeneity landscape. Genome Biol. 18, 220 (2017).

32. McGranahan, N. et al. Allele-Specific HLA Loss and Immune Escape in Lung Cancer Evolution. Cell 171, 1259-1271.e11 (2017).

33. Louveau, A. et al. Structural and functional features of central nervous system lymphatic vessels. Nature 523, 337-341 (2015).

34. Antila, S. et al. Development and plasticity of meningeal lymphatic vessels. J. Exp. Med. 214, 36453667 (2017).

35. Ahn, J. H. et al. Meningeal lymphatic vessels at the skull base drain cerebrospinal fluid. Nature $\mathbf{5 7 2}$, 62-66 (2019).

36. Hu, X. et al. Meningeal lymphatic vessels regulate brain tumor drainage and immunity. Cell Res. 30, 229-243 (2020). 
37. Banerji, S. et al. LYVE-1, a New Homologue of the CD44 Glycoprotein, Is a Lymph-specific Receptor for Hyaluronan. J. Cell Biol. 144, 789-801 (1999).

38. Noor, S. \& Wilson, E. H. Role of C-C chemokine receptor type 7 and its ligands during neuroinflammation. J. Neuroinflammation 9, 77 (2012).

39. Wigle, J. T. et al. An essential role for Prox1 in the induction of the lymphatic endothelial cell phenotype. EMBO J. 21, 1505-1513 (2002).

40. Louis, D. N. et al. The 2016 World Health Organization Classification of Tumors of the Central Nervous System: a summary. Acta Neuropathol. (Berl.) 131, 803-820 (2016).

41. Rogers, L. et al. Meningiomas: knowledge base, treatment outcomes, and uncertainties. A RANO review. J. Neurosurg. 122, 4-23 (2015).

42. Chen, W. C. et al. A Prognostic Gene-Expression Signature and Risk Score for Meningioma Recurrence After Resection. Neurosurgery (2020) doi:10.1093/neuros/nyaa355.

43. Prager, B. C. et al. The Meningioma Enhancer Landscape Delineates Novel Subgroups and Drives Druggable Dependencies. Cancer Discov. (2020) doi:10.1158/2159-8290.CD-20-0160.

44. Youngblood, M. W. et al. Correlations between genomic subgroup and clinical features in a cohort of more than 3000 meningiomas. J. Neurosurg. 1, 1-10 (2019).

45. Clark, V. E. et al. Recurrent somatic mutations in POLR2A define a distinct subset of meningiomas. Nat. Genet. 48, 1253-1259 (2016).

46. Paramasivam, N. et al. Mutational patterns and regulatory networks in epigenetic subgroups of meningioma. Acta Neuropathol. (Berl.) 138, 295-308 (2019).

47. Sievers, P. et al. YAP1-fusions in pediatric NF2-wildtype meningioma. Acta Neuropathol. (Berl.) 139, 215-218 (2020).

48. Williams, E. A. et al. Distinct genomic subclasses of high-grade/progressive meningiomas: NF2associated, NF2-exclusive, and NF2-agnostic. Acta Neuropathol. Commun. 8, 171 (2020).

49. Youngblood, M. W. et al. Associations of Meningioma Molecular Subgroup and Tumor Recurrence. Neuro-Oncol. (2020) doi:10.1093/neuonc/noaa226.

50. Sahm, F. et al. TERT Promoter Mutations and Risk of Recurrence in Meningioma. J. Natl. Cancer Inst. 108, (2016).

51. Spiegl-Kreinecker, S. et al. TERT promoter mutations are associated with poor prognosis and cell immortalization in meningioma. Neuro-Oncol. 20, 1584 (2018).

52. Shankar, G. M. \& Santagata, S. BAP1 mutations in high-grade meningioma: implications for patient care. Neuro-Oncol. 19, 1447 (2017).

53. Guyot, A. et al. Analysis of CDKN2A gene alterations in recurrent and non-recurrent meningioma. J. Neurooncol. 145, 449-459 (2019).

54. Appay, R. et al. CDKN2A homozygous deletion is a strong adverse prognosis factor in diffuse malignant IDH-mutant gliomas. Neuro-Oncol. 21, 1519-1528 (2019).

55. Merlo, A. et al. 5' CpG island methylation is associated with transcriptional silencing of the tumour suppressor p16/CDKN2/MTS1 in human cancers. Nat. Med. 1, 686-692 (1995).

56. Herman, J. G. et al. Distinct Patterns of Inactivation of p15INK4B and p16INK4A Characterize the Major Types of Hematological Malignancies. Cancer Res. 57, 837-841 (1997).

57. Rajeshwari, M. et al. Evaluation of chromosome 1q gain in intracranial ependymomas. J. Neurooncol. 127, 271-278 (2016). 
medRxiv preprint doi: https://doi.org/10.1101/2020.11.23.20237495; this version posted November 27, 2020. The copyright holder for this preprint (which was not certified by peer review) is the author/funder, who has granted medRxiv a license to display the preprint in perpetuity. It is made available under a CC-BY 4.0 International license .

58. O'Leary, B., Finn, R. S. \& Turner, N. C. Treating cancer with selective CDK4/6 inhibitors. Nat. Rev. Clin. Oncol. 13, 417-430 (2016).

59. Levine, A. J., Jenkins, N. A. \& Copeland, N. G. The Roles of Initiating Truncal Mutations in Human Cancers: The Order of Mutations and Tumor Cell Type Matters. Cancer Cell 35, 10-15 (2019). 
medRxiv preprint doi: https://doi.org/10.1101/2020.11.23.20237495; this version posted November 27, 2020. The copyright holder for this preprint (which was not certified by peer review) is the author/funder, who has granted medRxiv a license to display the preprint in perpetuity.

It is made available under a CC-BY 4.0 International license .

Fig. 1. Meningioma is comprised of 3 epigenetic groups with distinct clinical outcomes.

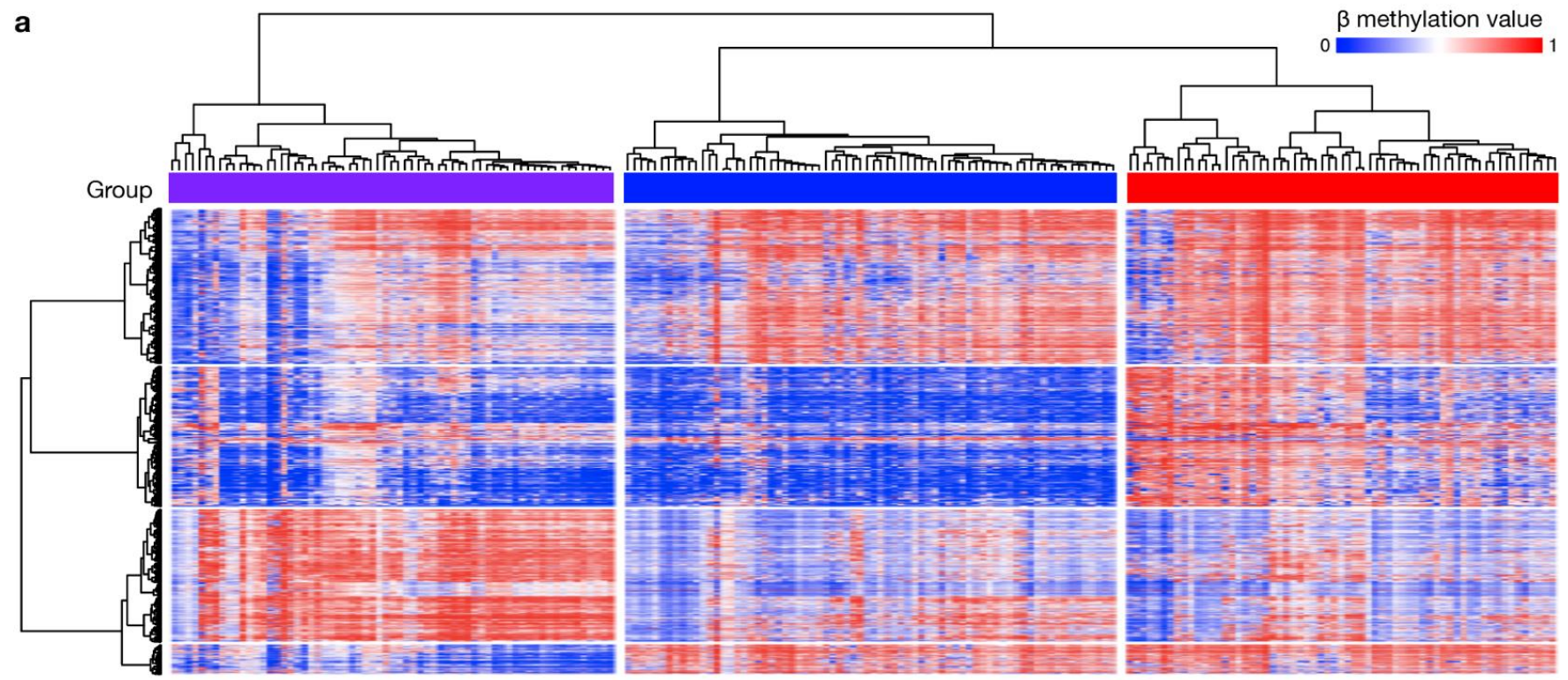

b
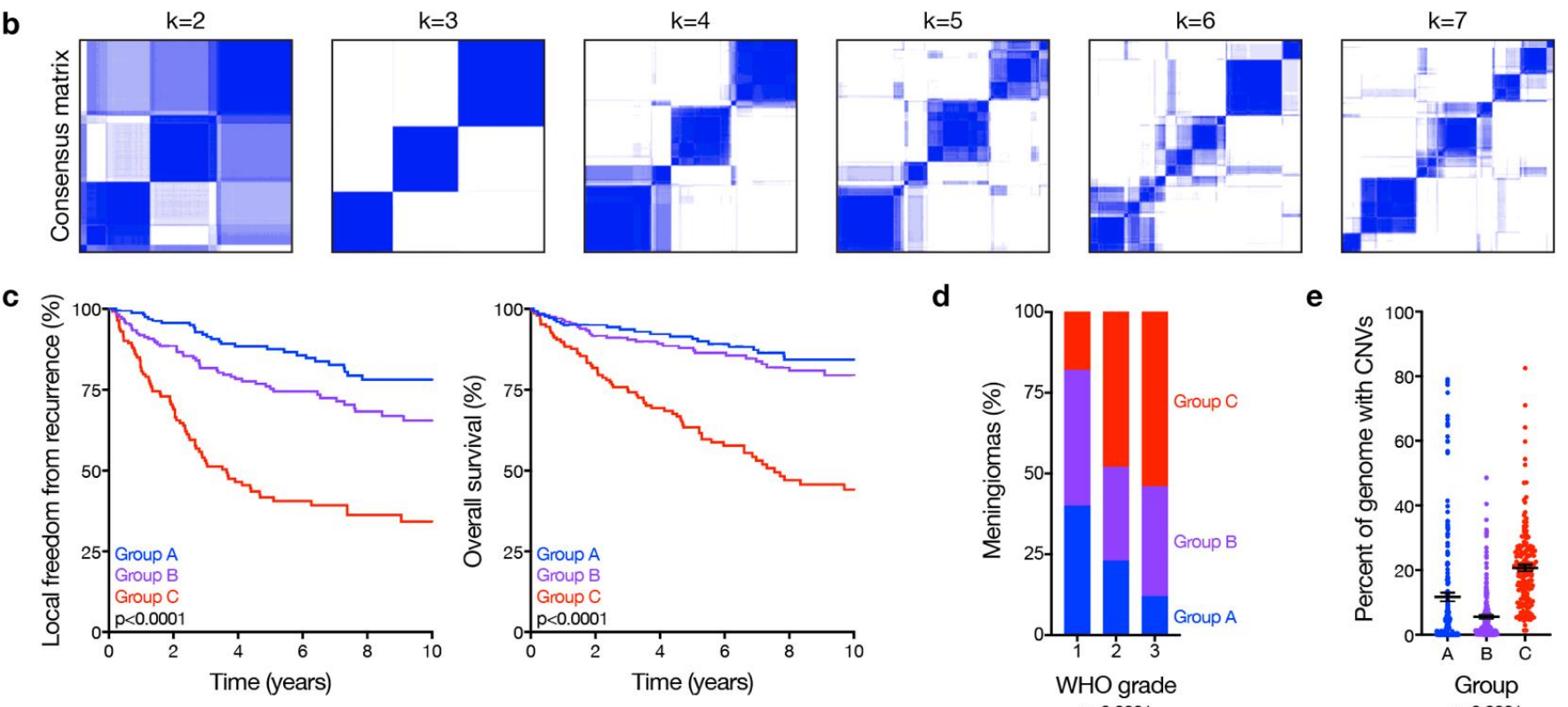

d

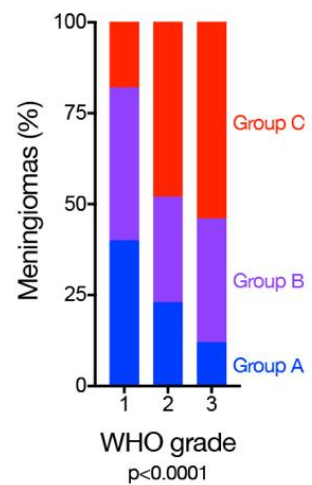

e

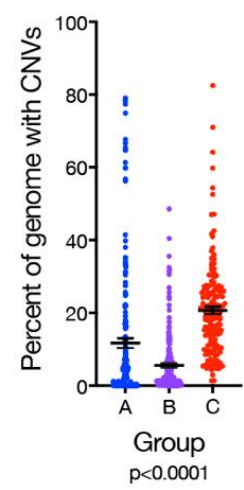


medRxiv preprint doi: https://doi.org/10.1101/2020.11.23.20237495; this version posted November 27, 2020. The copyright holder for this preprint (which was not certified by peer review) is the author/funder, who has granted medRxiv a license to display the preprint in perpetuity. It is made available under a CC-BY 4.0 International license .

Fig. 1. Meningioma is comprised of 3 epigenetic groups with distinct clinical outcomes.

a, Unsupervised hierarchical clustering of meningiomas from the discovery cohort $(n=200)$ using 2,000 differentially methylated DNA probes. b, K-means consensus clustering of meningiomas from the discovery and validation cohorts $(n=565)$. c, Kaplan-Meier curves for meningioma local freedom from recurrence and overall survival ( $n=565)$ across epigenetic groups (Log-rank tests). d, Meningioma World Health Organization (WHO) grades ( $n=565$ ) across epigenetic groups (Chi-squared test). e, Meningioma genomes ( $n=565)$ with copy number variations (CNVs) across epigenetic groups (ANOVA). 
medRxiv preprint doi: https://doi.org/10.1101/2020.11.23.20237495; this version posted November 27, 2020. The copyright holder for this preprint (which was not certified by peer review) is the author/funder, who has granted medRxiv a license to display the preprint in perpetuity.

It is made available under a CC-BY 4.0 International license .

Fig. 2. Meningioma loss of NF2/Merlin increases cell proliferation and decreases apoptosis.
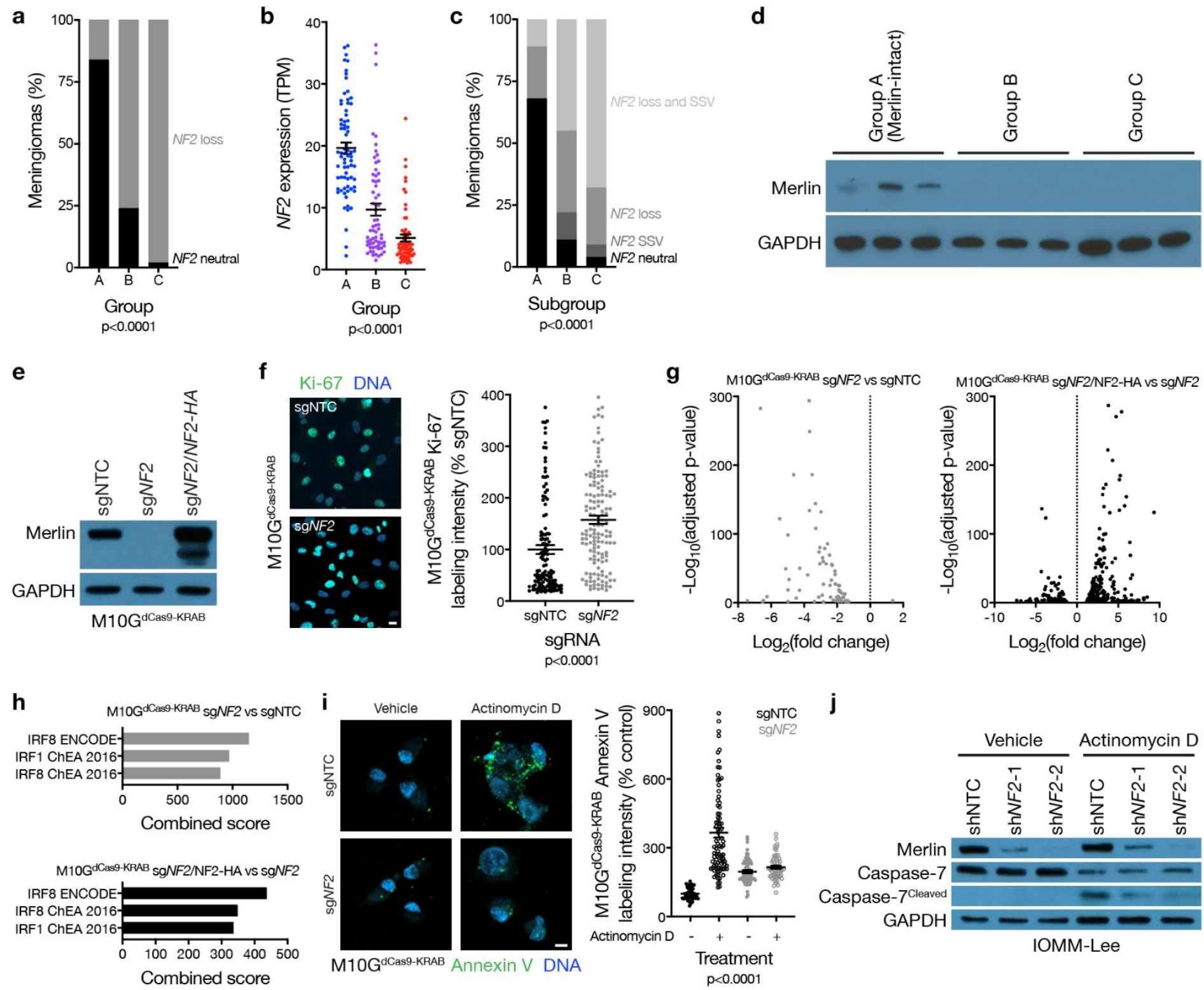
Fig. 2. Meningioma loss of NF2/Merlin increases cell proliferation and decreases apoptosis.

a, Meningioma DNA methylation-based analysis of copy number loss at the NF2 locus ( $n=565)$ across epigenetic groups (Chi-squared test). b, Meningioma transcripts per million (TPM) expression of NF2 $(n=200)$ across epigenetic groups (ANOVA). c, Meningioma $(n=65)$ NF2 copy number loss and targeted sequencing of somatic short variants (SSVs) across epigenetic groups (Chi-squared test). d, Immunoblot for Merlin and GAPDH in 3 meningiomas with NF2 loss at the NF2 locus from each epigenetic group. e, Immunoblot for Merlin and GAPDH in M10G ${ }^{\text {dCas9-KRAB }}$ cells stably expressing a non-targeting control single-guide RNA (sgNTC), a single-guide RNA targeting NF2 (sgNF2), or sgNF2 with concurrent Merlin rescue using an exogenous NF2 construct with an N-terminal HA tag. $\mathbf{f}$, Confocal immunofluorescence microscopy and quantification of Ki-67 in M10G ${ }^{\text {dCas9-KRAB }}$ cells from e (Student's t test). DNA is marked with Hoechst 33342. Scale bar $10 \mu \mathrm{M}$. g, Volcano plots of relative gene expression from RNA sequencing of M10G ${ }^{\text {dCas9-KRAB }}$ cells in $\mathbf{e . ~} \mathbf{h}$, Gene ontology analysis of differentially expressed genes downregulated from RNA sequencing of M10G ${ }^{d C a s 9-K R A B}$ cells in e. i, Confocal immunofluorescence microscopy and quantification of Annexin $\mathrm{V}$ in M10G ${ }^{\mathrm{dCas9}-\mathrm{KRAB}}$ cells from e treated with actinomycin D $0.5 \mu \mathrm{g} / \mathrm{m}$ or vehicle control for 48 hours (ANOVA). DNA is marked with DAPI. Scale bar $10 \mu \mathrm{M}$. j, Immunoblot for Merlin, Caspase-7, cleaved Caspase-7, or GAPDH in IOMM-Lee cells stably expressing non-targeting control shRNAs (shNTC) or shRNA targeting NF2 (shNF2-1 and shNF2-2) treated with actinomycin D or vehicle control as in i. 
medRxiv preprint doi: https://doi.org/10.1101/2020.11.23.20237495; this version posted November 27, 2020. The copyright holder for this preprint (which was not certified by peer review) is the author/funder, who has granted medRxiv a license to display the preprint in perpetuity.

It is made available under a CC-BY 4.0 International license .

Fig. 3. Meningioma immune enrichment is associated with HLA expression and meningeal lymphatics.
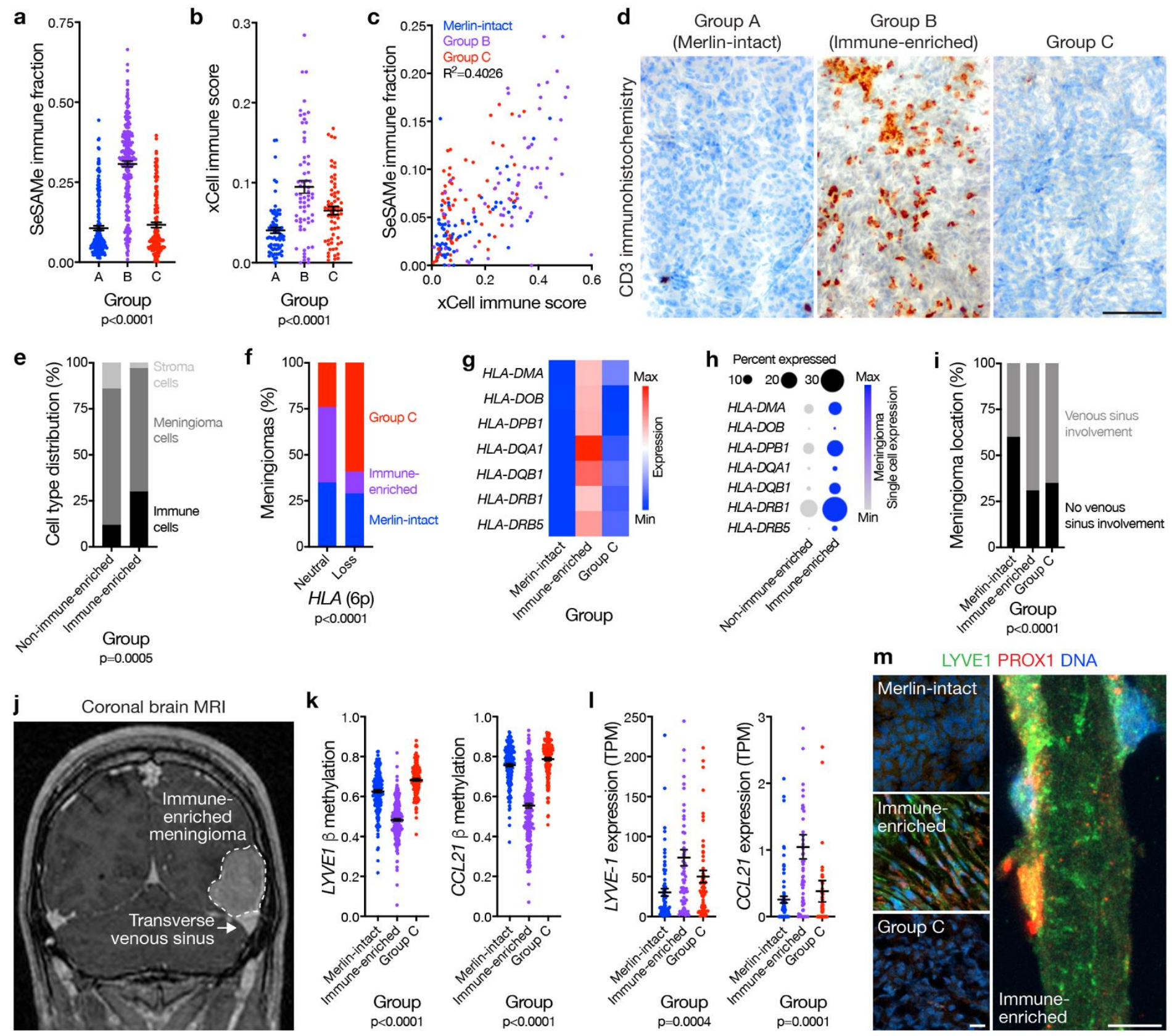
medRxiv preprint doi: https://doi.org/10.1101/2020.11.23.20237495; this version posted November 27, 2020. The copyright holder for this preprint (which was not certified by peer review) is the author/funder, who has granted medRxiv a license to display the preprint in perpetuity.

It is made available under a CC-BY 4.0 International license .

\section{Fig. 3. Meningioma immune enrichment is associated with HLA expression and meningeal lymphatics.}

a, Meningioma DNA methylation-based estimation of leukocyte fraction $(n=565)$ across epigenetic groups (ANOVA). b, Meningioma RNA sequencing-based $x$ Cell immune score $(n=200)$ across epigenetic groups (ANOVA). c, Correlation of meningioma leukocyte fraction from a and immune score from $\mathbf{b}(n=200)$ across epigenetic groups. $\mathbf{d}$, Representative images of meningioma CD3 immunohistochemistry $(n=87)$ across epigenetic groups $(p<0.0001$, Chi-squared test). Scale bar $100 \mu \mathrm{M}$. e, Single-cell RNA sequencing-based quantification of immune, stroma, and meningioma cells in Immune-enriched $(n=5)$ and non-Immune-enriched $(n=3)$ meningioma samples (Chi-squared test). $f$, Meningioma DNA methylation-based analysis of copy number loss at the HLA locus $(n=565)$ across epigenetic groups (Chisquared test). g, Meningioma RNA sequencing relative expression of $H L A$ genes $(n=200)$ across epigenetic group. $\mathbf{h}$, Meningioma single-cell RNA sequencing relative expression of $H L A$ genes across Immune-enriched $(n=5)$ and non-Immune-enriched $(n=3)$ meningioma samples. Circle size denotes percentage of cells. Circle shading denotes average expression. i, j Meningioma location on preoperative magnetic resonance imaging $(n=169)$ across epigenetic groups (Chi-squared test). Representative image shown. k, Meningioma DNA methylation ( $\mathrm{n}=565)$ of LYVE-1 (cg26455970) or CCL21 (cg27443224) across epigenetic groups (ANOVA). I, Meningioma transcripts per million (TPM) expression $(n=200)$ of LYVE-1 or CCL21 across epigenetic groups (ANOVA). $\mathbf{m}$, Representative images of meningioma LYVE1 and PROX1 confocal immunofluorescence microscopy across epigenetic groups $(n=12)$. DNA is marked with Hoechst 33342. Scale bars $10 \mu \mathrm{M}$. 
medRxiv preprint doi: https://doi.org/10.1101/2020.11.23.20237495; this version posted November 27, 2020. The copyright holder for this preprint (which was not certified by peer review) is the author/funder, who has granted medRxiv a license to display the preprint in perpetuity.

It is made available under a CC-BY 4.0 International license .

Fig. 4. Convergent genetic mechanisms misactive the cell cycle in meningioma.
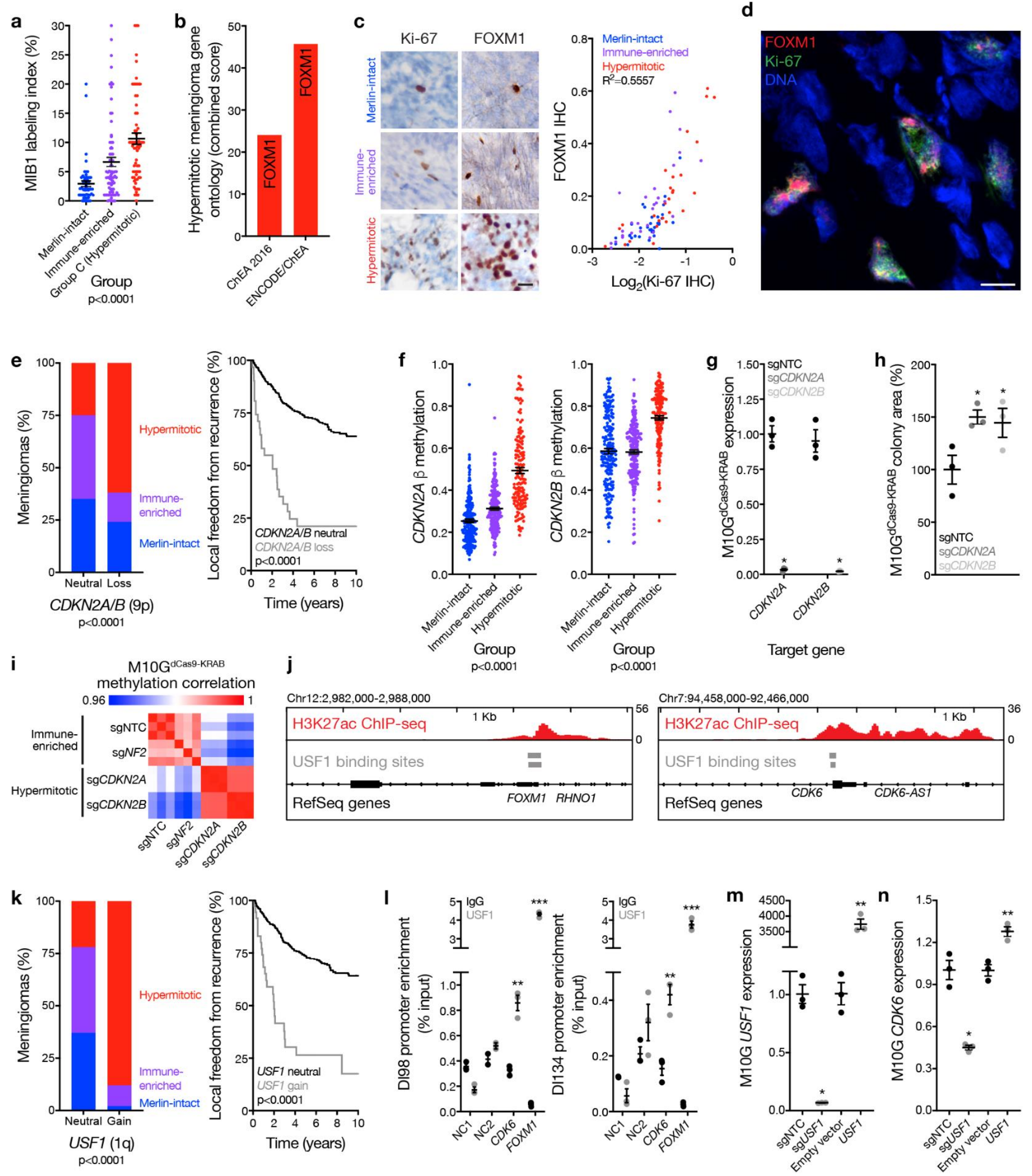
Fig. 4. Convergent genetic mechanisms misactivate the cell cycle in meningioma.

a, MIB1 labeling index from meningioma clinical pathology reports $(n=206)$ across epigenetic groups (ANOVA). b, Gene ontology analysis of differentially expressed genes in Hypermitotic meningiomas compared to tumors from other groups. ChEA, ChIP-X Enrichment Analysis. c, Representative images of meningioma Ki-67 and FOXM1 immunohistochemistry and correlated quantification $(\mathrm{n}=92)$ across meningioma groups. Scale bar $10 \mu \mathrm{M}$. d, Representative image of meningioma Ki-67 and FOXM1 confocal immunofluorescence microscopy. DNA is marked with DAPI. Scale bar $10 \mu \mathrm{M}$. e, Meningioma DNA methylation-based analysis of copy number loss at the CDKN2A/B locus across epigenetic groups (left, $n=565$, Chi-squared test), and Kaplan-Meier curve for meningioma local freedom from recurrence stratified by $C D K N 2 A / B$ copy number status (right, $\mathrm{n}=565$, Log-rank test). f, Meningioma DNA methylation $(\mathrm{n}=565)$ of $C D K N 2 A$ (cg26349275) or CDKN2B (cg208390209) across epigenetic groups (ANOVA). g,

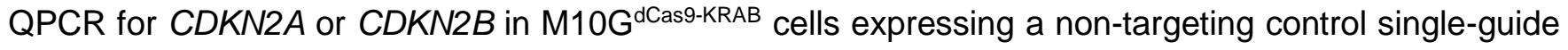
RNA (sgNTC), a single-guide RNA targeting the p16 1 INK4A isoform of CDKN2A (sgCDKN2A), or a singleguide RNA targeting $C D K N 2 B$ ( $\operatorname{sg} C D K N 2 B)\left({ }^{*} \mathrm{p}<0.05\right.$, Student's $\mathrm{t}$ test). $\mathbf{h}$, Relative colony area of M10G dCas9-KRAB cells expressing sgNTC, sgCDKN2A, or sgCDKN2B after 10 days of clonogenic growth $\left({ }^{*} \mathrm{p}<0.05\right.$, Student's $\mathrm{t}$ test). $\mathbf{i}$, Pearson correlation heatmap of all methylation probes for M10G ${ }^{\mathrm{dCas} 9-\mathrm{KRAB}}$ cells expressing sgNTC, sgNF2, sgCDKN2A, or sgCDKN2B ( $\mathrm{n}=3$ per condition). j, H3K27ac ChIP sequencing tracks comparing CDK6 and FOXM1 loci across meningiomas $(n=25)$ to normal neural cell and tissue samples (ChIP Atlas). USF1 binding sites are annotated. k, Meningioma DNA methylationbased analysis of copy number loss at the USF1 locus across epigenetic groups (left, $n=565$, Chi-squared test), and Kaplan-Meier curve for meningioma local freedom from recurrence stratified by USF1 copy number status (right, $n=565$, Log-rank test). I, ChIP-QPCR after USF1 pulldown in DI98 and DI134 meningioma cells for the CDK6 or FOXM1 promoters (Student's $t$ test) compared to negative control primers targeting a gene desert (NC1) or a gene not predicted to be bound by USF1 (NC2) from ChIP sequencing. $\mathbf{m}$, QPCR for USF1 in M10G ${ }^{\text {dCas9-KRAB }}$ cells expressing sgNTC or a single-guide RNA targeting USF1 (sgUSF1); or M10G cells expressing an empty vector or a vector containing exogenous USF1 (Student's t test). n, QPCR for CDK6 in M10G cells from $\mathbf{m}$ (Student's t test). * $\mathrm{p} \leq 0.05,{ }^{* *} \mathrm{p} \leq 0.01$, ${ }^{* * *} \mathrm{p} \leq 0.0001$. 
medRxiv preprint doi: https://doi.org/10.1101/2020.11.23.20237495; this version posted November 27, 2020. The copyright holder for this preprint (which was not certified by peer review) is the author/funder, who has granted medRxiv a license to display the preprint in perpetuity.

It is made available under a CC-BY 4.0 International license .

Fig. 5. Cell cycle inhibition blocks meningioma growth.

a

Epigenetic group $\mathrm{A}$

5- and 10 -year LFFR $88 \%$ and $78 \%$

5- and 10 -year OS $91 \%$ and $84 \%$

Description Merlin-intact

(TRAF7)

Primary meningioma MSC1 cell lines MSC5
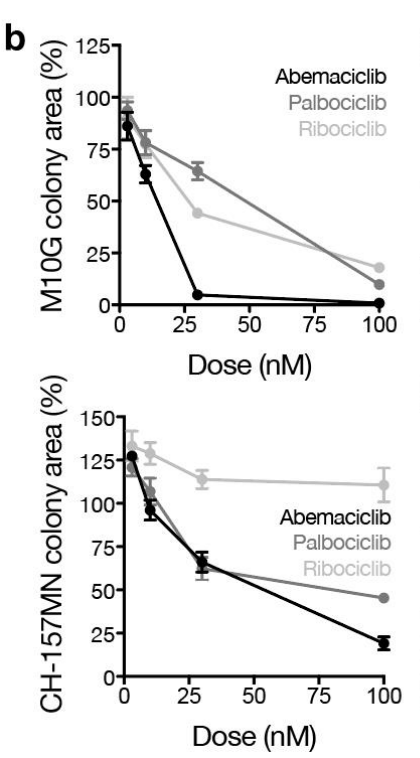

C

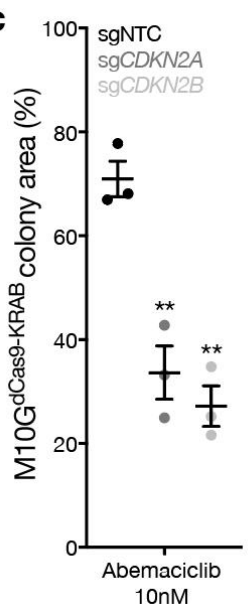

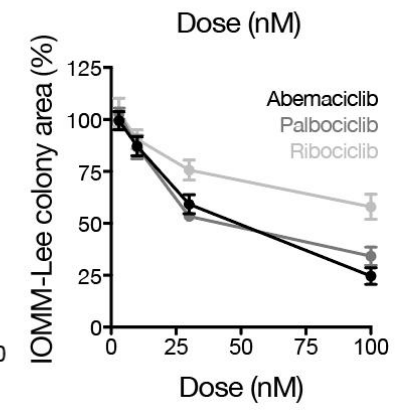

B C

$75 \%$ and $65 \% \quad 42 \%$ and $32 \%$

Immune-enriched Hypermitotic

NF2 (22q) loss

Meningeal lymphatics CDKN2A/B loss

USF1 gain

M10G M13C

D134 BenMen

IOMM-Lee

$\mathrm{CH}-157 \mathrm{MN}$
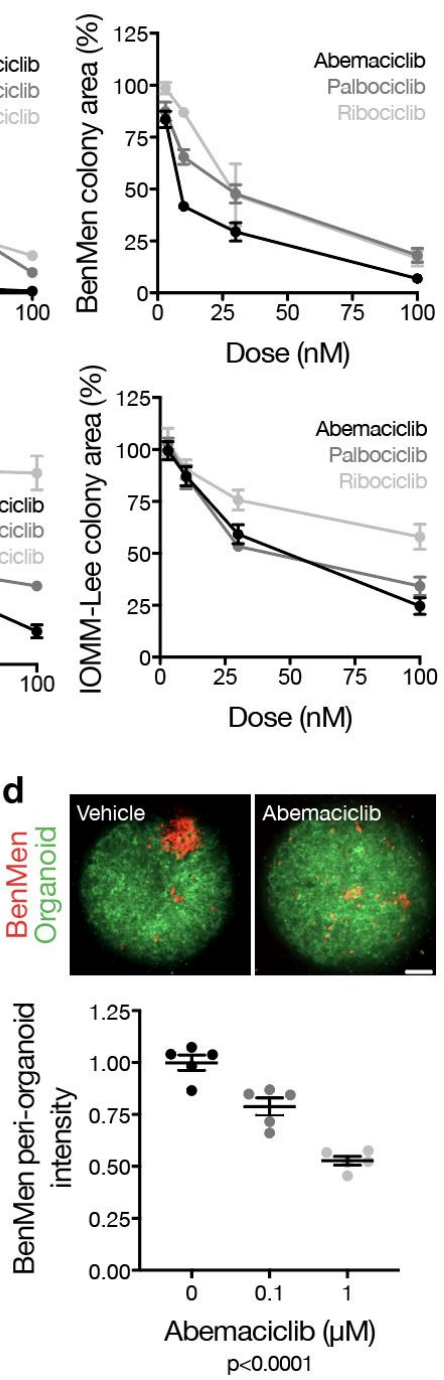

$87 \%$ and $80 \% \quad 63 \%$ and $44 \%$ e

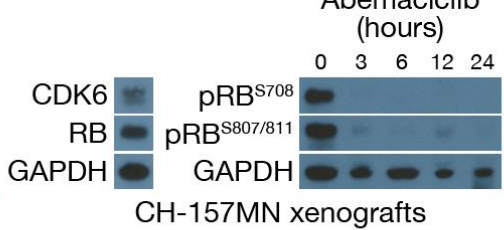

g
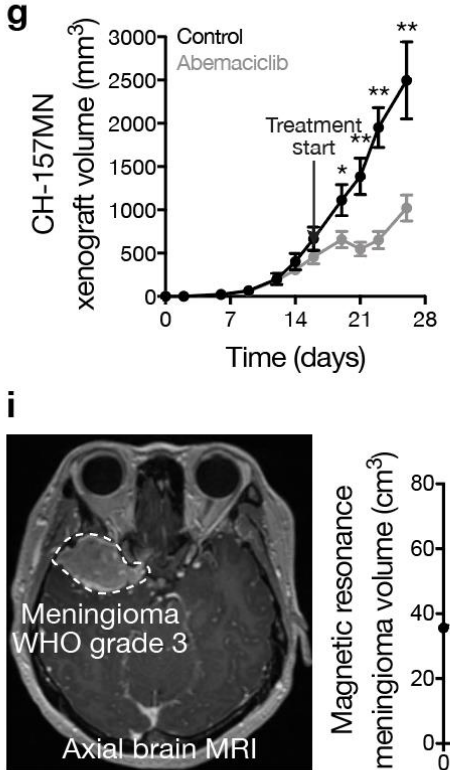

$\mathrm{Ki}-67$ labeling index $40 \%$

NF2 heterozygous loss and p.K20fs

CDKN2A/B homozygous loss

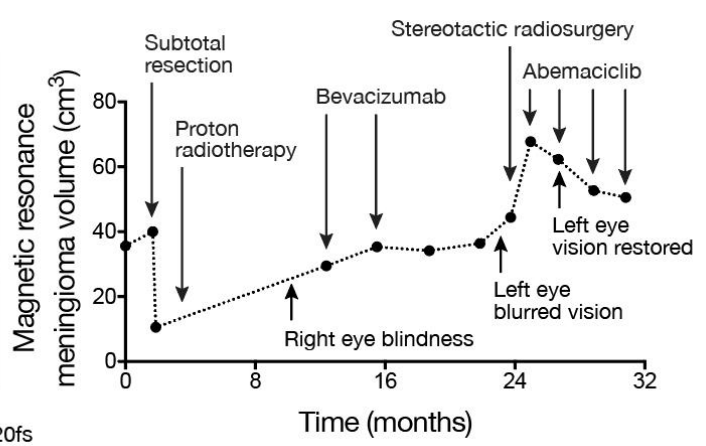

$1 p, 6 q, 9 q, 10,14 q, 18 p$ and $22 q$ loss

j

Points

Sex

Epigenetic group

WHO grade

Adjuvant radiotherapy

Extent of resection

Recurrent

MIB1 labeling index (\%)

Total Points

5-year LFFR probability

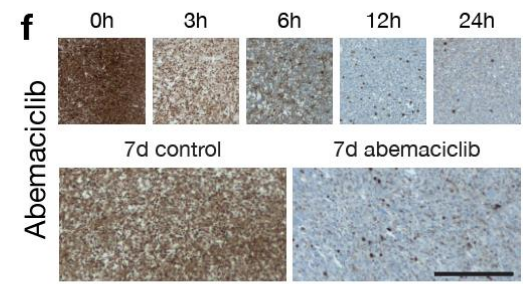

$\mathrm{CH}-157 \mathrm{MN}$ xenograft Ki-67

h

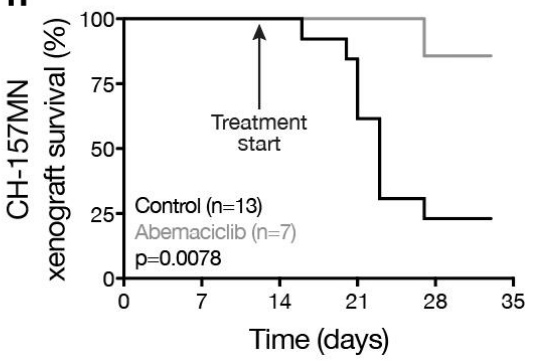

Time (days)

\begin{tabular}{l}
$80 \quad 90 \quad 100$ \\
\hline
\end{tabular}

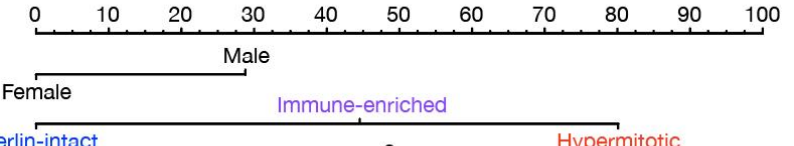

Merlin-intact 2 Hypermitotic

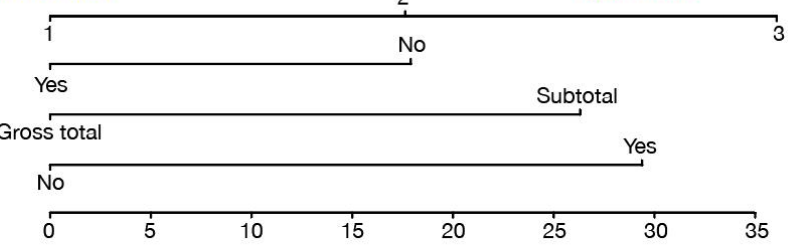

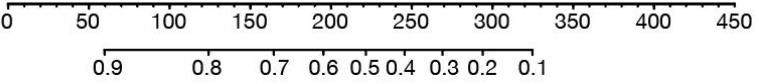


Figure 5. Cell cycle inhibition blocks meningioma growth.

a, Clinical outcomes and molecular features of meningioma epigenetic groups, and cell lines classifying in each group. b, Relative colony area of M10G, BenMen, $\mathrm{CH}-157 \mathrm{MN}$, or IOMM-Lee meningioma cells after 10 days of clonogenic growth and treatment with abemaciclib, ribociclib, or palbociclib. c, Relative colony area of M10G ${ }^{\text {dCas9-KRAB }}$ cells expressing sgNTC, sgCDKN2A, or sgCDKN2B after 10 days of clonogenic growth and treatment with abemaciclib (Student's t test). Data are normalized to growth with vehicle treatment of each cell lines. d, Quantification of BenMen peri-organoid intensity after 10 days of growth treatment with abemaciclib or vehicle control (ANOVA). Representative image of meningioma (red) and organoid (green) cells is shown. Scale bars $100 \mu \mathrm{M}$. e, Representative immunoblots from subcutaneous $\mathrm{CH}-157 \mathrm{MN}$ xenograft tumors in NU/NU mice (left) harvested at intervals after a single treatment of abemaciclib $(100 \mu \mathrm{g} / \mathrm{g}$ ) via oral gavage (right). f, Representative images of $\mathrm{CH}-157 \mathrm{MN}$ xenograft Ki-67 immunohistochemistry after a single (top) or daily (bottom) treatment of abemaciclib (100 $\mu \mathrm{g} / \mathrm{g}$ ) via oral gavage. Scale bar $1 \mathrm{mM}$. g, Subcutaneous $\mathrm{CH}-157 \mathrm{MN}$ xenograft measurements in NU/NU mice during daily oral gavage with abemaciclib $(100 \mu \mathrm{g} / \mathrm{g})$ versus control (Student's t test). $\mathbf{h}$, KaplanMeier curve for subcutaneous $\mathrm{CH}-157 \mathrm{MN}$ xenograft overall survival in NU/NU mice (Log-rank test). i, Magnetic resonance imaging and molecular features of a representative meningioma (left) that was resistant to cytotoxic therapies but responded to cell cycle inhibition (right). j, Nomogram for meningioma local freedom from recurrence (LFFR, $n=201$ ) integrating established clinical features and novel epigenetic groups. Each variable contributes points (top row) to the total score, which estimates the probably of 5-year LFFR (bottom 2 rows) (https://william-Cchen.shinyapps.io/RaleighLab MethylationSubgroupNomogram/). ${ }^{*} p \leq 0.05,{ }^{* *} p \leq 0.01,{ }^{* \star *} p \leq 0.0001$. 